NBER WORKING PAPER SERIES

\title{
INFORMATION IMMOBILITY AND THE HOME BIAS PUZZLE
}

\author{
Stijn Van Nieuwerburgh \\ Laura Veldkamp \\ Working Paper 13366 \\ http://www.nber.org/papers/w13366 \\ NATIONAL BUREAU OF ECONOMIC RESEARCH \\ 1050 Massachusetts Avenue \\ Cambridge, MA 02138 \\ August 2007
}

Thanks to Campbell Harvey and an anonymous associate editor and referee for their comments, which substantially improved the paper. Thanks also to Dave Backus, Pierre-Olivier Gourinchas, Urban Jermann, David Lesmond, Karen Lewis, Arzu Ozoguz, Hyun Shin, Chris Sims, Eric Van Wincoop, Mark Wright, participants at the following conferences: AFA, Banque de France conference on Economic Fluctuations Risk and Policy, Budapest SED, CEPR Asset Pricing meetings in Gerzensee, Cleveland Fed International Macroeconomics and Finance conference, Econometric Society, EEA, Financial Economics and Accounting, Financial Management Association, Prague workshop in macro theory, NBER EF\&G meetings and NBER summer institute in International Finance and Macro and seminar participants at Columbia GSB, Emory, Illinois, Iowa, GWU, LBS, LSE, Minneapolis Fed, MIT, New York Fed, NYU, Ohio State, Princeton, Rutgers, UCLA, UCSD, and Virginia for helpful comments and discussions. Laura Veldkamp thanks Princeton University for their hospitality and financial support through the Peter B. Kenen fellowship. The views expressed herein are those of the author(s) and do not necessarily reflect the views of the National Bureau of Economic Research.

(C) 2007 by Stijn Van Nieuwerburgh and Laura Veldkamp. All rights reserved. Short sections of text, not to exceed two paragraphs, may be quoted without explicit permission provided that full credit, including $(\mathrm{C}$ notice, is given to the source. 
Information Immobility and the Home Bias Puzzle

Stijn Van Nieuwerburgh and Laura Veldkamp

NBER Working Paper No. 13366

August 2007, Revised April 2008

JEL No. D82,F30,F40,G11,G14

\title{
ABSTRACT
}

Many argue that home bias arises because home investors can predict home asset payoffs more accurately than foreigners can. But why doesn't global information access eliminate this asymmetry? We model investors, endowed with a small home information advantage, who choose what information to learn before they invest. Surprisingly, even when home investors can learn what foreigners know, they choose not to: Investors profit more from knowing information others do not know. Learning amplifies information asymmetry. The model matches patterns of local and industry bias, foreign investments, portfolio out-performance and asset prices. Finally, we propose new avenues for empirical research.

\author{
Stijn Van Nieuwerburgh \\ Stern School of Business \\ New York University \\ $44 \mathrm{~W}$ 4th Street, suite 9-120 \\ New York, NY 10012 \\ and NBER \\ svnieuwe@stern.nyu.edu \\ Laura Veldkamp \\ Stern School of Business \\ New York University \\ 44 W Fourth Street, 7th Floor \\ New York, NY 10012 \\ and NBER \\ lveldkam@stern.nyu.edu
}


Observed returns on national equity portfolios suggest substantial benefits from international diversification, yet individuals and institutions in most countries hold modest amounts of foreign equity. Many studies document such home bias (see French and Poterba (1991), Tesar and Werner (1998) and Ahearne, Griever and Warnock (2004)). While restrictions on international capital flows may have been a viable explanation for the home bias thirty years ago, they no longer are today. An alternative hypothesis contends that home investors have superior access to information about domestic firms or economic conditions. This information-based theory of the home bias embeds the implicit assumption that home investors cannot learn about foreign firms. It replaces the old assumption of capital immobility by the similar assumption of information immobility. Our critique of this information-based theory of home bias is that domestic investors are free to learn about foreign firms. Such cross-border information flows could potentially undermine the home bias. In sum, when investors can choose which information to collect, initial information advantages could disappear.

Most existing models of asymmetric information in financial markets are silent on information choice. ${ }^{1}$ A small but growing literature studies how much information investors acquire about one risky asset or models a representative agent who, by definition, cannot have asymmetric information. ${ }^{2}$ Instead of asking how much investors learn, we ask which assets they learn about. To answer this question requires a model with three features: information choice, multiple risky assets to learn about, and heterogeneous agents so that information asymmetry is possible.

\footnotetext{
${ }^{1}$ Recent work on asymmetric information in financial markets includes Banerjee (2007), Ozdenoren and Yuan (2007) and Yuan (2005). The canonical reference on asymmetric information with multiple assets is Admati (1985). Work on asymmetric information and the home bias, in particular, includes Pastor (2000), Brennan and Cao (1997) and Portes, Rey and Oh (2001).

${ }^{2}$ Recent work on information choice in finance includes Peress (2006) and Dow, Goldstein and Guembel (2007). The canonical references in this literature, Grossman and Stiglitz (1980) and Admati and Pfleiderer (1990), are also about one risky asset. Our paper also differs from Calvo and Mendoza (2000) who argue that more scope for international diversification decreases the value of information. Our paper shows the converse: When investors can choose what to learn about, the value of diversification declines.
} 
We develop a two-country, rational expectations, general equilibrium model where investors first choose what home or foreign information to acquire, and then choose what assets to hold. The prior information home investors have about each home asset's payoff is slightly more precise than the prior information foreigners have. The reverse is true for foreign assets. This prior information advantage may reflect what is incidentally observed from the local environment. Home investors choose whether to acquire additional information about either home or foreign asset payoffs. The interaction of the information decision and the portfolio decision causes home investors to acquire information that magnifies their comparative advantage in home assets.

If home investors undo their information asymmetry by learning about foreign assets, they sacrifice excess returns. When information indicates that the foreign assets' payoffs will be high, both home and foreign investors know about it, demand more of the foreign assets, and bid up their price. If home investors instead learn more about home assets than the average investor does, then when they observe information indicating high home asset payoffs, home asset prices will not fully reflect this information. Prices reflect only as much as the the average investor knows. The difference between prices and expected payoffs generates home investors' expected excess return.

When choosing what to learn, investors make their information set as different as possible from the average investor's. To achieve the maximum difference, home investors take home assets, which they start out knowing relatively more about, and specialize in learning even more about them. The main result in the first half of the paper is that information immobility persists not because investors cannot learn what locals know, nor because it is expensive, but because they do not choose to; specializing in what they already know is a more profitable strategy. Having shown that sustaining information asymmetry is possible, the second half of the paper compares the testable predictions of the model to the data. 
The model's key mechanism is the interaction between the information choice and the investment choice. To illustrate its importance, section II shuts down this interaction by forcing investors to take their portfolios as given, when they choose what to learn. These investors minimize investment risk by learning about assets that they are most uncertain about. With sufficient capacity, learning undoes all initial information advantage, and therefore all home bias. Thus, this model embodies the logic that the asymmetric information criticisms are founded on.

Section III shows that when investors have rational expectations about their future optimal portfolio choices, this logic is reversed. While acquiring information that others do not know increases expected portfolio returns, that alone does not imply that home investors take a long position in home assets, only that they take a large position. Home bias, a long position in the home asset that exceeds what is prescribed by the standard world market portfolio, arises because home assets offer risk-adjusted expected excess returns to informed home investors. Information about the home asset reduces the risk or uncertainty that the asset poses without reducing its return, hence the high risk-adjusted returns. How does information reduce uncertainty? An asset's payoff may be very volatile, high one period and low the next. But if an investor has information that tells him when the payoff is high and when it is low, the asset payoff is not very uncertain to that investor. Information drives a wedge between the conditional standard deviation (uncertainty or risk) and the unconditional standard deviation (volatility) of asset payoffs. While foreign assets offer lower risk-adjusted returns to home investors, they are still held for diversification purposes. The optimal portfolio tilts the world market portfolio towards home assets.

Considering how learning affects portfolio risk offers an alternative way of understanding why investors with an initial information advantage in home assets choose to learn more about home assets. Because of the excess risk-adjusted returns, a home investor with a small information 
advantage initially expects to hold slightly more home assets than a foreign investor would. This small initial difference is amplified because information has increasing returns in the value of the asset it pertains to: as the investor decides to hold more of the asset, it becomes more valuable to learn about. So, the investor chooses to learn more and hold more of the asset, until all his capacity to learn is exhausted on his home asset.

A variety of evidence supports the model's predictions. Section IV connects the theory to facts about analyst forecasts, portfolio patterns, excess portfolio returns, cross-sectional asset prices, as well as evidence thought to be incompatible with an information-based home bias explanation. In particular, the theory offers a unified explanation of home bias and local bias. While we cannot claim for any one of these facts that no other theory could possibly explain the same relationship, taken together, they constitute a large body of evidence that is consistent with one parsimonious theory. A numerical example shows that learning can magnify the home bias considerably. When all home investors get a small initial advantage in all home assets, the home bias is between 5 and $46 \%$, depending on the magnitude of investors' learning capacity. When each home investor gets an initial information advantage that is concentrated in one local asset, the home bias is amplified. It rises as high as the $76 \%$ home bias in U.S. portfolio data, for a level of capacity that is consistent with observed excess returns on local assets. Finally, we derive new testable hypotheses from the model to guide future empirical work.

Information advantages have been used to explain exchange rate fluctuations (Evans and Lyons (2005), Bacchetta and van Wincoop (2006)), the international consumption correlation puzzle (Coval (2003)), international equity flows (Brennan and Cao (1997)), a bias towards investing in local stocks (Coval and Moskowitz (2001)), and the own-company stock puzzle (Boyle, Uppal and Wang (2003)). Information asymmetry also sustains other home bias explanations, such as ambiguity 
aversion (Uppal and Wang (2003)). All of these explanations are bolstered by our finding that information advantages are not only sustainable when information is mobile, but that asymmetry can be amplified when investors can choose what to learn.

\section{A Model of Learning and Investing}

Using tools from information theory, we construct an equilibrium framework to consider learning and investment choices jointly. This model uses the one-investor partial-equilibrium problem of Van Nieuwerburgh and Veldkamp (2008) to build a heterogeneous-agent, two-country general equilibrium model with a continuum of investors in each country. This is a static model which we break up into 3 periods. In period 1, each investor chooses the distribution from which to draw signals about the payoff of the assets, subject to a constraint on the total informativeness of their signals. In period 2, each investor observes signals from the chosen distribution and makes his investment. Prices are set such that the market clears. In period 3, he receives the asset payoffs and consumes.

Preferences Investors, with absolute risk aversion parameter $\rho$, facing an $N \times 1$ vector of unknown asset payoffs $f$ a risk-free rate $r$ and asset prices $p$, maximize their mean-variance utility:

$$
U=-E\left[-\rho q^{\prime}(f-r p)+\frac{\rho^{2}}{2} q^{\prime} \widehat{\Sigma} q\right]
$$

where $q$ is the $N \times 1$ vector of quantities of each asset the investor decides to hold and $\widehat{\Sigma}$ is the uncertainty about payoffs that investors face after they learn. ${ }^{3}$ When portfolios are chosen in period 2, the expectation $E$ is conditional on the realization of the signals the investor has chosen

\footnotetext{
${ }^{3}$ A separate appendix discusses the foundations for this utility formulation in detail. Also, the results do not depend on the existence of a risk-free asset. Suppose investors can consume $c_{1}$ at the investment date and $c_{2}$ when asset payoffs are realized. If preferences are defined over $r c_{1}+c_{2}$, where $r$ is the rate of time preference, the solution will be identical. The earlier consumption choice takes the place of the riskless investment choice.
} 
to see. When signals are chosen at time 1, the investor does not know what the realizations of these signals will be. Therefore, in period 1 , the investor has the same objective, except that expectation $E$ conditions only on information in prior beliefs. This utility function comes from an exponential form of utility over terminal wealth. Terminal wealth equals initial wealth $W_{0}$, plus the profit earned from portfolio investments:

$$
W=r W_{0}+q^{\prime}(f-p r)
$$

Initial information Two countries, home and foreign, have an equal-sized continuum of investors, whose preferences are identical. Investors are endowed with prior beliefs about a vector of asset payoffs $f$. Each investor's prior belief is an unbiased, independent draw from a normal distribution, whose variance depends on where the investor resides. Home prior beliefs are $\mu \sim N(f, \Sigma)$. Foreign prior beliefs are distributed $\mu^{\star} \sim N\left(f, \Sigma^{\star}\right)$. Home investors have lower-variance prior beliefs for home assets and foreign investors have lower-variance beliefs for foreign assets. One interpretation is that each investor gets a free signal about each asset in his home country. We will call this difference in prior variances a group's initial information advantage.

Information acquisition Each investor knows the true mean and variance of asset payoffs. The only unknown is the realization of those payoffs $f$, which is what the investor can learn about. Just like an econometrician, he can acquire additional data to form a more accurate payoff estimate $\hat{\mu}$. The investor chooses what assets to collect data on, subject to a constraint on the total amount of data. Collecting more data on one asset reduces the standard error of his estimate for that asset's payoff. The posterior variance is that standard error, squared.

At time 2, each investor will observe an $N \times 1$ vector of signal realizations $\eta$ about the vector of 
asset payoffs $f$. At time 1 , investors choose a variance $\Sigma_{\eta}$ such that $\eta \sim N\left(f, \Sigma_{\eta}\right)$. Investors cannot choose whether signals will contain good or bad news. Rather, they choose signals that will contain more precise information about some assets than others. Each investor's signal is independent of the signals drawn by other investors.

When payoffs co-vary, obtaining a signal about one asset's payoff is informative about other payoffs. To describe what a signal is about, it is useful to decompose asset payoff risk into orthogonal risk factors and the risk of each factor. This decomposition breaks the prior variance-covariance matrix $\Sigma$ up into a diagonal eigenvalue matrix $\Lambda$, and an eigenvector matrix $\Gamma: \Sigma=\Gamma \Lambda \Gamma^{\prime}$. The $\Lambda_{i}$ 's are the prior variances of each risk factor $i$. The $i$ th column of $\Gamma\left(\operatorname{denoted} \Gamma_{i}\right)$ contains the loadings of each asset on the $i$ th risk factor. To make aggregation tractable, we assume that home and foreign prior variances $\Sigma$ and $\Sigma^{\star}$ have the same eigenvectors, but different eigenvalues. In other words, home and foreign investors use their capacity to reduce different initial levels of uncertainty about the same set of risks. This assumption implies that investors observe signals $\left(\Gamma^{\prime} \eta\right)$ about risk factor payoffs $\left(\Gamma^{\prime} f\right)$. Learning about risk factors (principal components analysis) has long been used in financial research and among practitioners. It approximates risk categories investors might study: country risk, business cycle risk, industry, regional, and firm-specific risk. Nothing prevents investors from learning about many risk factors. The only thing this rules out is signals with correlated information about independent risks.

Choosing how much to learn about each risk factor is equivalent to choosing the variance of each entry of the $N \times 1$ signal vector $\Gamma^{\prime} \eta$. Since the signal is unbiased, its mean is $\Gamma^{\prime} f$. The variance of a principal component is its eigenvalue. So, reducing uncertainty about the $i$ th risk factor means choosing a smaller $i$ th eigenvalue of the signal variance-covariance matrix $\Sigma_{\eta}$. Signals about the payoffs of all assets that load on risk factor $i$ become more accurate. With Bayesian updating, each 
$\Sigma_{\eta}$ results in a unique posterior variance matrix that measures the investor's uncertainty about asset payoffs, after incorporating what he learned. Since the mapping between signal choices and posteriors is unique, information choice is the same as choosing posterior variance, without loss of generality. Since sums, products and inverses of prior and signal variance matrices have eigenvectors $\Gamma$, posterior beliefs will as well. Denoting posterior beliefs with a hat, $\widehat{\Sigma}=\Gamma \hat{\Lambda} \Gamma^{\prime}$, where $\Gamma$ is given and the diagonal eigenvalue matrix $\hat{\Lambda}$ is the choice variable. The decrease in risk factor $i$ 's posterior variance $\left(\Lambda_{i}-\hat{\Lambda}_{i}\right)$ measures the decrease in uncertainty achieved through learning.

There are 2 constraints governing how the investor can choose his signals about risk factors. The first is the capacity constraint; it limits the quantity of information investors can observe. Grossman and Stiglitz (1980) used the ratio of variances of prior and posterior beliefs to measure the quality of information about one risky asset. We generalize this metric to a multi-signal setting by bounding the ratio of the generalized prior variance to the generalized posterior variance, $|\widehat{\Sigma}| \geq \frac{1}{K}|\Sigma|$, where generalized variance is defined as the determinant of the variance-covariance matrix. Capacity $K \geq 1$ measures how much an investor can decrease the uncertainty he faces. For now, $K$ is the same for all investors. Since determinants are a product of eigenvalues, the capacity constraint is

$$
\prod_{i} \hat{\Lambda}_{i} \geq \frac{1}{K} \prod_{i} \Lambda_{i}
$$

The second constraint is the no negative learning constraint: the investor cannot choose to increase uncertainty (forget information) about some risks to free up more capacity to decrease uncertainty about other risks. We rule this out by requiring the variance-covariance matrix of the signal vector $\Sigma_{\eta}=\Gamma \Lambda_{\eta} \Gamma^{\prime}$, to be positive semi-definite. Since a matrix is positive semi-definite when 
all its eigenvalues are positive, the constraint is:

$$
\Lambda_{\eta i} \geq 0 \quad \forall i
$$

This constraint implies that $\hat{\Lambda}_{i}^{-1} \geq \Lambda_{i}^{-1}+\Lambda_{p i}^{-1}, \forall i$.

Comments on the learning technology The structure we put on the learning problem keeps it as simple as possible. But many of these assumptions can be relaxed. First, our results do not hinge on the assumption that investors learn about principal components of asset payoffs. Investors specialize in what they know well, for any arbitrary risk factor structure. Second, our framework can incorporate capacity which differs across investors (see section IV.C). Third, allowing agents to choose how much capacity to acquire does not change the results. Any cost function increasing in $K$ has an equivalent capacity endowment that produces identical portfolio outcomes. Finally, a learning technology with diminishing returns and un-learnable risk will moderate, but not overturn, our results. Instead of specializing in one risk, investors may learn about a limited set of risks. But it does not change the conclusion that investors prefer to learn about what they already have an advantage in. ${ }^{4}$

It is not true that every capacity constraint preserves specialization. We use this one because it is a common distance measure in econometrics (a log likelihood ratio) and in statistics (a KullbackLiebler distance); it is a bound on entropy reduction, an information measure with a long history in information theory (Shannon (1948)); it can be interpreted as a technology for reducing measurement error (Hansen and Sargent (2001)); it is a measure of information complexity (Cover and Thomas (1991)); it has been used to forecast foreign exchange returns (Glodjo and Harvey (1994)),

\footnotetext{
${ }^{4}$ The proof of the first and third claims can be found in the separate appendix, the proof of the last claim is in Van Nieuwerburgh and Veldkamp (2008).
} 
and it has been used to describe limited information processing ability in economic settings by (Sims (2003)). ${ }^{5}$ Although we do not prove this is the correct learning technology, our strategy is to work out its predictions for international investment choices and ask whether they are consistent with the data.

Updating beliefs When investors' portfolios are fixed (section II), what investors learn does not affect the market price. But when asset demand responds to observed information (section III), the market price is an additional noisy signal of this aggregated information. Using their prior beliefs, their chosen signals, and information contained in prices, investors form posterior beliefs about asset payoffs, using Bayes' law.

The information in prices depends on portfolio choices. Appendix B shows that prices $p$ are linear functions of the true asset payoffs such that $(r p-A) \sim N\left(f, \Sigma_{p}\right)$, for some constant $A$.

An investor $j$ 's posterior belief about the asset payoff $f$, conditional on a prior belief $\mu^{j}$, signal $\eta^{j} \sim N\left(f, \Sigma_{\eta}^{j}\right)$, and prices, is formed using Bayesian updating. The posterior mean is a weighted average of the prior, the signal and price information, while the posterior variance is a harmonic mean of the prior, signal, and price variances:

$$
\begin{gathered}
\hat{\mu}^{j} \equiv E\left[f \mid \mu^{j}, \eta^{j}, p\right]=\left(\left(\Sigma^{j}\right)^{-1}+\left(\Sigma_{\eta}^{j}\right)^{-1}+\Sigma_{p}^{-1}\right)^{-1}\left(\left(\Sigma^{j}\right)^{-1} \mu^{j}+\left(\Sigma_{\eta}^{j}\right)^{-1} \eta^{j}+\Sigma_{p}^{-1}(r p-A)\right) \\
\hat{\Sigma}^{j} \equiv V\left[f \mid \mu^{j}, \eta^{j}, p\right]=\left(\left(\Sigma^{j}\right)^{-1}+\left(\Sigma_{\eta}^{j}\right)^{-1}+\Sigma_{p}^{-1}\right)^{-1} .
\end{gathered}
$$

We emphasize that acquiring information $\left(\left(\Sigma_{\eta}^{j}\right)^{-1}>0\right)$ always reduces posterior variance. This

\footnotetext{
${ }^{5}$ This learning technology is also used in models of rational inattention. However, that work has focused on time-series phenomena in representative investor models such as delayed response to shocks, inertia, time to digest, and consumption smoothing. See e.g. Sims (2003) and Moscarini (2004). Instead, we focus on the interactions of heterogeneous investors' learning choices.
} 
might appear puzzling because in an econometric setting, new data can make us revise variance estimates upward. The difference is that there is no estimation of variance in our problem. The true variance of $f$ is known to all investors. Rather, $\widehat{\Sigma}$ is the variance of the estimate of $f$. It is a measure of uncertainty, a posterior variance which conditions on the investor's information, not of volatility (prior variance). Under Bayes' law with normal random variables, more information always reduces uncertainty. ${ }^{6}$

Market clearing Asset prices $p$ are determined by market clearing. The per-capita supply of the risky asset is $\bar{x}+x$, a positive constant $(\bar{x}>0)$ plus a random $(n \times 1)$ vector with known mean and variance, and zero covariance across assets: $x \sim N\left(0, \sigma_{x}^{2} I\right)$. The reason for having a risky asset supply is to create some noise in the price level that prevents investors from being able to perfectly infer the private information of others. Without this noise, no information would be private, and no incentive to learn would exist. We interpret this extra source of randomness in prices as due to liquidity or life-cycle needs of traders. The market clears if investors' portfolios $q^{j}$ sum to the asset supply: $\int_{0}^{1} q^{j} d j=\bar{x}+x$.

Definition of Equilibrium An equilibrium is a set of asset demands, asset prices and information choices, such that three conditions are satisfied. First, given prior information about asset payoffs $f \sim N(\mu, \Sigma)$, each investor's information choice $\hat{\Lambda}$ and portfolio choice $q$ maximize (1), subject to capacity (3), no-negative-learning (4) and budget constraints (2). Second, asset prices are set such that the asset market clears. Third, beliefs are updated, using Bayes' law (5 and 6) and expectations are rational: Period-1 beliefs about the portfolio $q$ are consistent with the true distribution of the optimal $q$.

\footnotetext{
${ }^{6}$ Our model does not distinguish between risk and uncertainty because the probability of each of the states of nature is known.
} 


\section{Why Might Asymmetric Information Disappear?}

Returns to specialization come from the interaction of the investment choice and the learning choice. To highlight the importance of this interaction, we first explore a model where it is shut down. The only difference with the main model in section III is that investors do not account for the fact that what they learn will influence the portfolio they hold. They take their portfolio as given and choose what to learn, in order to minimize its risk. In this setting, investors learn exclusively about the most uncertain assets until either they run out of capacity, or are equally uncertain about all assets. Learning undoes initial information advantages and reduces or eliminates home bias. As Lewis (1999) put it, "Greater uncertainty about foreign returns may induce the investor to pay more attention to the data and allocate more of his wealth to foreign equities." This section explains the basis for this criticism of information-based models of the home bias.

In order to shut down the investment-learning interaction, we assume that the investor takes the vector of asset holdings $q$ as given and expected to hold the same amount of each risk factor: $\Gamma_{i}^{\prime} q=\Gamma_{k}^{\prime} q, \forall i, k$. The objective (1) collapses to choosing $\hat{\Lambda}_{i}$ 's to minimize $\sum_{i}\left(\Gamma_{i}^{\prime} q\right)^{2} \hat{\Lambda}_{i}$, subject to the capacity constraint (3) and the no-forgetting constraint (4). The following result shows that learning undoes initial information asymmetry. The proofs of this and all subsequent propositions are in appendix A.

Proposition 1. Information Acquisition in a Model without Increasing Returns to Information. There exists a threshold $K^{\star}$ such that, if capacity is $K \geq K^{\star}$, then the optimal information allocation choice for an investor who takes asset holdings $q$ as given is to set $\hat{\Lambda}_{i}=M$

for all risk factors $i \in\{1, \cdots, N\}$, for some constant $M>0$, irrespective of his initial information advantage. If $K<K^{\star}$, then $\hat{\Lambda}_{i}=\min \left\{\Lambda_{i}, M\right\}$. 
The proposition states that an investor who believes that he will hold equal amounts of each home and foreign risk factor, optimally chooses to equate the posterior variance across all risk factors (to some target variance $M$ ), given enough capacity $K^{\star}$. With high enough learning capacity, having an initial advantage in home or foreign risk will result in the same the same posterior variances for both home and foreign assets. Learning choices compensate for initial information advantage in such a way as to render the nature of the initial advantage irrelevant. Any home bias that might result from the information advantage disappears when investors can learn.

On the other hand, if capacity is sufficiently low, then equating posterior precisions on all assets is not feasible. The no-forgetting constraint prevents the investor from reducing her information about the home assets to free up capacity to learn about the foreign assets. The constrained optimum is to set posterior variances equal as much as possible. This allocation implies devoting capacity to the most uncertain risk factor first. For a home investor with an initial advantage in home risk factors and small capacity, this means using all capacity to learn about foreign risk factors. Therefore, initial information advantages could persist if capacity were low relative to the initial advantage. However, if this explanation were true, individuals would never choose to learn about home assets; they would devote what little information capacity they had entirely to learning about foreign assets. This implication seems inconsistent with the multi-billion-dollar industry that analyzes U.S. stocks, reports on the U.S. economy, manages portfolios of U.S. assets, and then sells their products to American investors.

A second mechanism that might preserve a home information advantage is a higher cost of processing foreign information. While foreign information is likely harder to learn, this cost difference must be large to account for the magnitude of the home bias. ${ }^{7}$ Since there is no theory to

\footnotetext{
${ }^{7}$ The technical appendix computes this required cost.
} 
predict information costs and they are not observable, it is desirable for a theory not to rely on the magnitude of the cost difference. Instead, the model in the next section requires an arbitrarily small initial information advantage, possibly generated by a small cost difference, to endogenously create a large home bias.

\section{Main Results}

The previous section illustrated how information asymmetry could disappear. This section analyzes a model where small differences in investors' information not only persist, but are magnified. The only change in the setup is that investors do not take their asset demand, or the asset demand of other investors, to be fixed. Instead, we apply rational expectations: every investor takes into account that every portfolio in the market depends on what each investor learns. We conclude that home investors can learn foreign information, but choose not to. They achieve higher expected utility from specializing in what they already know.

\section{A The Period-2 Portfolio Problem}

We solve the model using backward induction, starting with the optimal portfolio decision, taking

information choices as given. Given posterior mean $\hat{\mu}^{j}$ and variance $\widehat{\Sigma}^{j}$ of asset payoffs, the portfolio for investor $j$, from either country, is

$$
q^{j}=\frac{1}{\rho}\left(\widehat{\Sigma}^{j}\right)^{-1}\left(\hat{\mu}^{j}-p r\right) .
$$

Aggregating these asset demands across investors and imposing market clearing delivers a solution for the equilibrium asset price level that is linear in the asset payoff $f$ and the unexpected component 
of asset supply $x: p=\frac{1}{r}(A+f+C x)$. Appendix B derives formulas for $A$ and $C$.

\section{B The Optimal Learning Problem}

In period 1, the investor chooses information to maximize expected utility. In order to impose rational expectations, we substitute the equilibrium asset demand (7), into expected utility (1). Combining terms yields

$$
U=E\left[\frac{1}{2}\left(\hat{\mu}^{j}-p r\right)^{\prime}\left(\widehat{\Sigma}^{j}\right)^{-1}\left(\hat{\mu}^{j}-p r\right) \mid \mu, \Sigma\right]
$$

At time $1,\left(\hat{\mu}^{j}-p r\right)$ is a normal variable, so that $U$ s the mean of a chi-squared distributed random variable. The separate appendix shows that we can rewrite the period- 1 objective as:

$$
\max _{\hat{\Lambda}^{j}} \sum_{i}\left(\Lambda_{p i}+\left(\rho \Gamma_{i}^{\prime} \bar{x} \hat{\Lambda}_{i}^{a}\right)^{2}\right)\left(\hat{\Lambda}_{i}^{j}\right)^{-1} \quad \text { s.t. (3) and (4) }
$$

where $\Lambda_{p i}$ is the $i$ th eigenvalue of $\Sigma_{p}$, and $\hat{\Lambda}_{i}^{a} \equiv\left(\int_{j}\left(\hat{\Lambda}^{j}\right)^{-1}\right)^{-1}$ is the posterior variance of risk factor $i$ for a hypothetical average investor.

The key feature of the learning problem (9) is its convexity in the posterior variance $\left(\hat{\Lambda}^{j}\right)$. To illustrate, consider a setting with one risk factor in each country, where the objective is $U=$ $L_{1} / \hat{\Lambda}_{1}+L_{2} / \hat{\Lambda}_{2}$ for positive scalars $L_{1}$ and $L_{2}$. Thus, an indifference curve is $\hat{\Lambda}_{2}=L_{2} \hat{\Lambda}_{1} /\left(U \hat{\Lambda}_{1}-L_{1}\right)$, which asymptotes to $\infty$ at $\hat{\Lambda}_{1}=L_{1} / U>0$. The capacity constraint is $\hat{\Lambda}_{2}=K / \hat{\Lambda}_{1}$, which asymptotes to $\infty$ at $\hat{\Lambda}_{1}=0$. Because the indifference curve is always crossing the capacity constraint from below, the solution is always a corner solution.

Figure 1 plots the indifference curve (for $L_{1}=L_{2}$ ), the capacity constraint, and the no-negative learning bounds for our model (left panel) and the exogenous-portfolio model in section 2 (right 

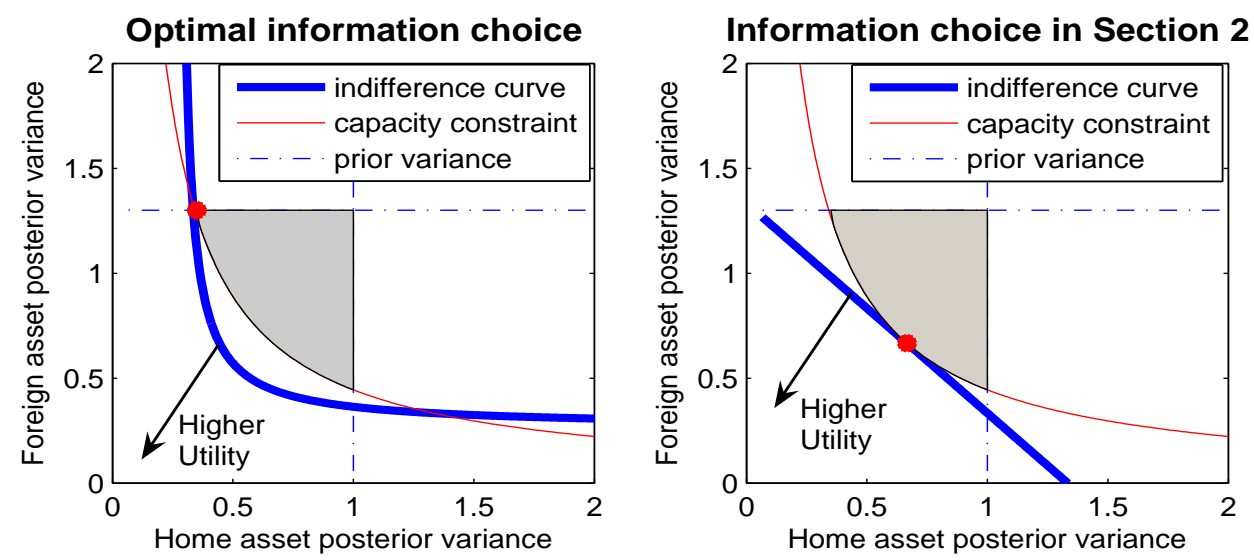

Figure 1: Objective and constraints in the optimal learning problem with 2 risk factors.

panel). Utility increases as the indifference curve (dark line) moves toward the origin (variance falls). All feasible learning choices must lie on or above the capacity constraint (lighter line). The no-negative learning constraint prohibits posterior variances from exceeding prior variances (dashed lines). The set of learning choices that satisfy both constraints is the shaded area. Whenever foreign prior variance is higher than home prior variance, as in the figure, the solution in our model is to devote all capacity to reducing home asset risk (the large dot in the left panel). In the model of section 2 (right panel), the objective is linear and the optimum is to reduce variance on home and foreign assets until their posterior variances are equal. The right panel shows why shutting down the information-portfolio interaction reverses our main conclusion.

The following proposition states that each investor $j$ uses his entire capacity $K$ to learn about one risk factor's payoff $f^{\prime} \Gamma_{i}$. The risk factor the investor chooses to devote his capacity to has the highest value of the learning index.

Definition. Investor $j$ 's learning index for risk factor $i$ is $\mathcal{L}_{i}^{j} \equiv\left(\rho \hat{\Lambda}_{i}^{a} \Gamma_{i}^{\prime} \bar{x}\right)^{2}\left(\left(\Lambda_{i}^{j}\right)^{-1}+\Lambda_{p i}^{-1}\right)+\frac{\Lambda_{p i}}{\Lambda_{i}^{j}}$.

Proposition 2. Optimal Information Acquisition. The optimal information allocation decision for each investor $j$ takes the following form: $\hat{\Lambda}_{k}^{j}=\Lambda_{k}^{j}$ for all $k \neq i$ and $\hat{\Lambda}_{i}^{j}<\Lambda_{i}^{j}$ for risk factor 
$i$, where $i=\arg \max _{\ell=1, \cdots, N}\left\{\mathcal{L}_{\ell}^{j}\right\}$.

Three features make a particular risk factor $i$ desirable to learn about. First, the larger the risk factor, measured by the supply $\left(\Gamma_{i}^{\prime} \bar{x}\right)^{2}$, the higher its learning index. Since one piece of information can be used more profitably to evaluate one hundred shares of an asset than one share, information has increasing returns, and the investor gains more from learning about a risk that is abundant. Second, the investor should learn about a risk factor that the average investor is uncertain about (high $\hat{\Lambda}_{i}^{a}$ ). These risk factors have prices that reveal less information (high $\Lambda_{p i}$ ), and have higher expected returns: $\Gamma_{i}^{\prime} E[f-p r]=\rho \hat{\Lambda}_{i}^{a} \Gamma_{i}^{\prime} \bar{x}$. (See appendix B for a derivation.) Third, and most importantly for the point of the paper, the investor should learn about risk factors that he has less initial uncertainty about, relative to the average investor (high $\hat{\Lambda}_{i}^{a} / \Lambda_{i}$ ). Since these are the assets he will expect to hold more of, these are more valuable to learn about.

The feedback effects of learning and investing can be seen in the learning index. The amount of a risk factor that an investor $j$ expects to hold, based on his prior and price information, is the factor's expected return, divided by variance: $\rho \hat{\Lambda}_{i}^{a} \Gamma_{i}^{\prime} \bar{x}\left(\left(\Lambda_{i}^{j}\right)^{-1}+\Lambda_{p i}^{-1}\right)$. This expected portfolio holding shows up in the learning index formula, indicating that a higher expected portfolio share increases the value of learning about the risk factor. Expecting to learn more about the risk factor lowers the posterior variance $\hat{\Lambda}_{i}^{j}$. Re-computing the expected portfolio holding with variance $\hat{\Lambda}_{i}^{j}$, instead of $\left(\left(\Lambda_{i}^{j}\right)^{-1}+\Lambda_{p i}^{-1}\right)^{-1}$, further increases factor $i$ 's portfolio share, and feeds back to increase $i$ 's learning index. This interaction between the learning choice and the portfolio choice, an endogenous feature of the model, generates increasing returns to specialization.

Strategic Substitutability Because other investors' learning lowers the posterior uncertainty $\hat{\Lambda}_{i}^{a}$ and the informativeness of prices $\Lambda_{p i}$ for the risk factors $i$ they learn about, each investor prefers 
to learn about risk factors that other investors do not learn about: $\frac{\partial \mathcal{L}_{i}^{j}}{\hat{\Lambda}_{i}^{a}}>0$. This is strategic substitutability. Let $\mathcal{I}^{h}$ be the set of risk factors that home investors learn about. Since all home investors are ex-ante identical, each home investor $j$ is indifferent between learning about any of these risk factors: $\mathcal{L}_{i}^{j}=\mathcal{L}_{k}^{j}$ for any $i, k \in \mathcal{I}^{h}$. There is another such set of risk factors $\mathcal{I}^{f}$ for foreign investors. The number of risk factors in each set depends on country-wide information capacity. Despite their indifference, the incentive to specialize ensures that each investor will learn about only one risk factor. While a given investor can learn about any single asset in his indifference set in equilibrium, strategic substitutability ensures that the aggregate allocation of capacity is unique. ${ }^{8}$

Learning and Information Asymmetry The effect of an initial information advantage on learning is similar to the effect of a comparative advantage on trade. Home investors always have a higher learning index than foreigners do for home risks, and vice-versa for foreign risks. If home risks are particularly valuable to learn about, for example because those risks are large (high $\left.\Gamma_{i}^{\prime} \bar{x}\right)$, some foreigners may choose to learn about them. But, if home risks are valuable to learn about, all home investors will specialize in them. Likewise, if some home investors learn about foreign risks, then all foreigners must be specializing in foreign risks as well. The one pattern the model rules out is that home investors learn about foreign risk and foreigners learn about home risk. This is analogous to the principle of comparative advantage: If country A has an advantage in producing apples and country $\mathrm{B}$ an advantage in bananas, the one production pattern that is not possible is that country A produces bananas and B apples. Investors never make up for their initial information asymmetry by each learning about the others' advantage. Instead, posterior beliefs

\footnotetext{
${ }^{8}$ For proofs of strategic substitutability and equilibrium uniqueness, see section A of the technical appendix. In what follows, we consider a symmetric mixed strategy equilibrium where, for each risk factor $i$ and any two investors $j, j^{\prime}$, if $\mathcal{L}_{i}^{j} \geq \mathcal{L}_{i}^{j^{\prime}}$ then the probability that investor $j$ learns about $i$ is at least as high as the probability that $j^{\prime}$ learns about $i$.
} 
diverge, relative to priors; information asymmetry is amplified.

Let $\Lambda_{h}\left(\Lambda_{h}^{*}\right)$ denote home (foreign) investors' prior variance for an arbitrary home risk factor $h$, and let $\hat{\Lambda}_{h}\left(\hat{\Lambda}_{h}^{*}\right)$ denote the average home (foreign) investor's posterior variance for $h$.

Proposition 3. Learning Amplifies Information Asymmetry. For every home risk factor $h, \hat{\Lambda}_{h}^{-1}-\left(\hat{\Lambda}_{h}^{*}\right)^{-1} \geq \Lambda_{h}^{-1}-\left(\Lambda_{h}^{*}\right)^{-1}$.

A special case of this result arises when home and foreign countries are perfectly symmetric: They have an equal number of risk factors of equal size with equal payoff variances. In this case, home investors learn exclusively about home risks and foreign investors learn exclusively about foreign risks. This result follows directly from the learning index in proposition 2. An investor with no information advantage would have identical learning indices for home and foreign risks. Thus, he would be indifferent between learning about home and foreign risks. Since investors with no information advantage are indifferent, any initial advantage in home risk $i$ (lower $\Lambda_{i}^{j}$ in the learning index) breaks that indifference, tilts preferences toward learning more about home risk and amplifies the initial advantage.

At the other extreme, with very asymmetric markets, amplification disappears. If the home market is much smaller than the foreign market, the learning index for the foreign risk factors would be much higher for both the home and the foreign investor, and all investors optimally learn about foreign risk factors. The ratio of home and foreign investors' posterior precisions will then be the same as the ratio of their prior precisions. The initial advantage is just preserved.

For all intermediate cases, posterior belief differences between foreign and home investors about home assets are greater than prior belief differences. This leads us to conclude that learning amplifies the initial information advantage. 


\section{Home Bias in Investors' Portfolios}

To understand the effect of learning on home bias, we compare our model's predictions to two benchmark portfolios. The first portfolio would arise as the optimal portfolio in an economy with no information advantage and no capacity to learn. Home investors and foreign investors have identical beliefs and hold identical portfolios, which depend on the random asset supply. The expected portfolio is the per capita expected supply: $E\left[q^{d i v}\right]=\bar{x}$. It is the world market portfolio, the perfectly diversified portfolio of home and foreign assets.

A second natural benchmark portfolio is one where investors have initial information advantages and can process the information in prices, but cannot acquire signals: $E\left[q^{\text {no learn }}\right]=\Gamma\left(\left(\Lambda^{j}\right)^{-1}+\right.$ $\left.\Lambda_{p}^{-1}\right)\left(\frac{1}{2} \Lambda^{-1}+\frac{1}{2}\left(\Lambda^{*}\right)^{-1}+\Lambda_{p}^{-1}\right)^{-1} \Gamma^{\prime} \bar{x}$, for an investor $j \cdot{ }^{9}$ For comparison, note that the no-advantage portfolio can be written as $E\left[q^{d i v}\right]=\Gamma I \Gamma^{\prime} \bar{x}$. What makes the no-learning portfolio different from the no-advantage portfolio is the initial information advantage: $\left(\Lambda^{j}\right)^{-1} \neq \frac{1}{2} \Lambda^{-1}+\frac{1}{2}\left(\Lambda^{*}\right)^{-1}$. The no-learning portfolio tilts away from the world market portfolio towards the risk factors that the investor has an initial advantage in. For example, this is the kind of information advantage that Ahearne et al. (2004) capture when they estimate the home bias that uncertainty about foreign accounting standards could generate.

The optimal expected portfolio with information acquisition takes the form:

$$
E[q]=\Gamma \hat{\Lambda}^{-1} \hat{\Lambda}^{a} \Gamma^{\prime} \bar{x}
$$

Specialization in learning does not imply specialization in portfolio holdings. Even if an investor only learns about one home risk factor, he still holds all other assets for diversification purposes.

\footnotetext{
${ }^{9}$ Section A of the separate appendix derives all portfolio expressions.
} 
Each investor $j$ 's optimal portfolio takes the world market portfolio $(\bar{x})$ and tilts it towards the assets $i$ that he knows more about than the average investor (high $\left.\left(\hat{\Lambda}_{i}^{j}\right)^{-1} \hat{\Lambda}_{i}^{a}\right)$.

Let $\bar{\Gamma}_{h}$ be a sum of the eigenvectors in $\Gamma$ which correspond to the home risk factors. Then $\bar{\Gamma}_{h}^{\prime} q$ quantifies how much total home risk an investor is holding in his portfolio.

Definition. The home bias in a portfolio $q$ is the difference between the home risk exposure in $q$ and in the diversified portfolio: $\mathcal{H}^{j}(q) \equiv E\left[\bar{\Gamma}_{j}^{\prime} q\right]-E\left[\bar{\Gamma}_{j}^{\prime} q^{\text {div }}\right]$, for an investor $j \in\{h, f\}$.

The final proposition shows that the home bias in the optimal portfolio (10) exceeds the home bias in the no-learning portfolio.

Proposition 4. Learning Increases Home Bias. The home bias is larger when investors can learn than when they cannot: $\mathcal{H}^{j}(q) \geq \mathcal{H}^{j}\left(q^{\text {no learn }}\right)$, for an investor $j \in\{h, f\}$.

Learning has two effects on an investors' portfolio. First, it magnifies the asset position and second, it tilts the portfolio towards the assets learned about. The first effect can be seen in (10): Learning increases the precision of beliefs $\hat{\Lambda}^{-1}>\Lambda^{-1}+\Lambda_{p}^{-1}$. Lower risk in factor $i$ makes investors want to take larger positions in $i$, positive or negative. But why should the position in home assets be a large long position, rather than a large short one? The second effect is an equilibrium effect. The return on an asset compensates the average investor for the amount of risk he bears $\hat{\Lambda}_{i}^{a}$. The fact that foreign investors are investing in home assets without knowing much about them (typically as part of a diversified portfolio), raises $\hat{\Lambda}^{a}$ and thus the asset's return. Home investors $j$ are being compensated for more risk than they bear $\left(\hat{\Lambda}_{i}^{a}>\hat{\Lambda}_{i}^{j}\right)$. In other words, the home assets deliver high risk-adjusted returns. High returns make a long position optimal, on average. Both the magnitude and the general equilibrium effect increase home bias. ${ }^{10}$

\footnotetext{
${ }^{10}$ It is possible that a highly negative signal realization on a home asset would make home investors who are
} 


\section{Bringing the Theory to Data}

There are a number of recent papers that present alternative explanations for home bias. Some of these explanations are behavioral: Huberman (2001) explores familiarity, Cohen (2007) explores loyalty, Morse and Shive (2008) propose patriotism, while Graham, Harvey and Huang (2006) investigate overconfidence. Other argue, like this paper does, that home bias is the outcome of rational investor choice: Cole, Mailath and Postlewaite (2001) and DeMarzo, Kaniel and Kremer (2004) claim that investors have preference-based or market-price-based incentives to hold portfolios similar to their neighbors'. At the same time, there has been an active literature that attempts to distinguish between the various theories by documenting facts related to the home bias. While each fact taken alone may be explained by alternative theories, it is difficult to find one parsimonious theory that can explain a large set of facts. Rather than adding new facts, this section taps in to the existing empirical literature and connects the theory to the evidence, qualitatively and quantitatively (sections A and B). It also reconciles existing facts that appear to be at odds with an information explanation (section $\mathrm{C}$ ) and offers new predictions to guide future empirical work (section D).

\section{A Facts That Support Model Predictions}

Direct Evidence of Information Asymmetry Bae, Stulz and Tan (2008) measure information asymmetry and link it to home bias. They show that home analysts in 32 countries make more precise earnings forecasts for home stocks than foreign analysts do. On average, the increase in precision is $8 \%$. Furthermore, the size of the home analyst advantage is related to home bias.

informed want to short that asset. Short selling is unlikely to occur on a large scale in general equilibrium, however. The dramatic fall in prices from widespread shorting would signal the bad news to foreign investors, making them unwilling to take the opposite large long positions. Low prices would also make home investors more willing to hold home assets, despite their low payoffs. 
When local analysts' forecasts are more precise relative to foreigners' forecasts (more information asymmetry), foreign investors hold less of that country's assets.

Guiso and Jappelli (2006) examine survey data on the time customers of a leading Italian bank spend acquiring financial information. Those who spend more time on information collection hold portfolios that are less diversified and earn significantly higher returns.

Local Bias Home bias is not just a country-level effect. Investors also favor local assets, headquartered near their home, over firms in the same country located further away (Coval and Moskowitz (2001)). A unified explanation for home and local bias is something that many theories cannot provide. Their coexistence makes an information-based explanation appealing. Malloy (2005) offers direct evidence that local analysts do in fact have information advantages. He shows that local analysts' forecasts better predict stock returns and that they earn abnormal returns on their local assets. By giving investors slightly more precise initial information about local assets, this model can explain the local bias.

Suppose that home investors each had an advantage in only one home risk factor, the one most concentrated in their region's asset. An investor $j$ from region $m$ draws an independent prior belief $\mu^{j} \sim N\left(f, \Sigma_{m}\right)$, where $\Sigma_{m}=\Gamma \Lambda_{m} \Gamma$, and $\Lambda_{m}$ has a $m$ th diagonal entry that is lower than it is for investors from other regions. In this model, local investors have an incentive to learn more about their local assets, because of their initial information advantage (proposition 2). Local advantages also amplify the effects of home advantages: When fewer investors share an advantage in the same local risk, locals have a larger advantage relative to the average investor (higher $\hat{\Lambda}_{m}^{a} / \Lambda_{m}^{j}$ in the learning index). A more specialized advantage magnifies the optimal portfolio bias $\left(E\left[\Gamma_{m}^{\prime} q\right]=\hat{\Lambda}_{m}^{a} / \Lambda_{m}^{j}\left(\Gamma_{m}^{\prime} \bar{x}\right)\right)$. Because returns to specialization increase when information advantages 
are more concentrated, investors diversify less. We illustrate this amplification effect in section B.

Industry Bias One source of prior information advantages could be one's industry. If so, investors should reinforce that information asymmetry by learning more about that industry and investing more in it. Massa and Simonov (2006) confirm this prediction. They show that Swedish investors buy assets closely related to their non-financial income. Two facts make the authors conclude that the portfolio bias could be information-driven. When an investor changes industries, his holdings of assets in that industry decline. More importantly, "familiarity-based" portfolios yield higher returns than diversified ones.

Another source of prior information is one's classmates. Cohen, Frazzini and Malloy (2007) find that fund managers over-invest in firms run by their former classmates and make excess returns on those investments. This is consistent with an initial information advantage acquired in school.

Under-diversified Foreign Investment One feature of portfolio data that is difficult to explain is the concentration within the foreign component of home investors' portfolios. The part of a portfolio invested in any given foreign country should therefore be diversified. Kang \& Stulz (1997) show that this is not the case. Using data on foreign investors in Japan, they show that foreigners' portfolios of Japanese assets overweight large firms and assets whose returns correlate highly with aggregate risk.

This pattern is consistent with our model. Suppose than an American investor chooses to learn about and invest in Japanese assets. Holding equal the average uncertainty $\left(\hat{\Lambda}^{a}\right)$, noise in prices $\left(\Lambda_{p}\right)$ and American prior uncertainty $(\Lambda)$ about each Japanese risk, the most valuable risk to reduce is the one with the largest quantity (highest $\Gamma_{i} \bar{x}$ in proposition 2). In other words, the American should learn about the largest risk factors, aggregate macroeconomic risk and the risks associated 
with the largest firms. Since investors, on average, hold more of the assets they've learned about, the model predicts that Americans who hold Japanese assets will not diversify their Japanese holdings. Instead, they will overweight large, high-beta firms.

Portfolio Out-performance If transaction costs or behavioral biases are responsible for underdiversification, then concentrated portfolios should deliver no additional profit. In contrast, if investors in our model concentrate their portfolios, it is because they have informational advantages. Their concentrated portfolios should out-perform diversified ones. ${ }^{11}$

There is empirical evidence for such out-performance. Ivkovic, Sialm and Weisbenner (2007) find that concentrated investors outperform diversified ones by as much as $3 \%$ per year. Outperformance is even higher for investments in local stocks, where natural informational asymmetries are most likely to be present (see also Coval and Moskowitz (2001), Massa and Simonov (2006) and Ivkovic and Weisbenner (2005)). If fund managers have superior information about stocks in particular industries, they should outperform in these industries. Kacperczyk, Sialm and Zheng (2005) show that funds with above-median industry concentration yield an average return that is $1.1 \%$ per year higher than those with below-median concentration.

The model also predicts that home investors should out-perform foreign investors on home assets. Choe, Kho and Stulz (2005) document home asset out-performance by Korean investors. While one might think that this is only true for individual investors, Hau (2001) documents excess German-asset returns for professional traders in Germany. Similarly, Shukla and van Inwegen (1995) document that US mutual funds earn higher returns on US assets than UK funds do. Dvorak (2007) argues that Indonesian investors outperform foreigners on Indonesian assets, even

\footnotetext{
${ }^{11}$ On-line technical appendix $\mathrm{C}$ proves that concentrated portfolios achieve higher expected returns. It also uses the theory to interpret measures of portfolio risk.
} 
when that investment is intermediated by a professional.

Cross-sectional Asset Returns Investors want to learn information others do not know because assets that many other investors learn about have high prices and low expected returns. Thus a falsifiable prediction of the model is its negative relationship between information and expected returns. Three studies confirm this prediction. First, Botosan (1997) and Easley, Hvidkjaer and O'Hara (2002) find that more public information lowers an asset's return. Second, Pastor and Veronesi (2003) find that firms with more abundant historical data offer lower returns. Finally, Greenstone, Oyer and Vissing-Jorgenson (2006) analyze a mandatory disclosure law that changed a group of firms from being low-information to high-information. They find that between proposal and passage of the law, prices of the most affected firms rose, producing abnormal excess returns of 11-22\%. After passage, excess returns disappeared. Our model only speaks to the last example by way of a comparative static: firms with more public information have a lower $\hat{\Lambda}^{a}$ and higher prices. It seems conceivable that a dynamic extension of the model could generate a slow information diffusion process during which stock prices gradually increase.

\section{B Quantitative Evaluation: Is capacity large enough?}

A key unobserved variable in the model is the investor's capacity, which regulates how much he can learn. This exercise infers capacity from estimates of portfolio out-performance. The test is: Does this inferred level of capacity deliver observed home bias? This is a useful test because it tells us if home bias is rationalized by profit-maximization. Before proceeding, we first explore how asset correlation and local information affect the optimal degree of home bias.

Two countries have 1000 identical investors each. The 5 home and 5 foreign assets are all uncorrelated. Foreigners start out $\alpha$ times more uncertain about home risks $(1+\alpha) \Lambda_{h}=\Lambda_{h}^{\star}$, and 
home investors are $\alpha$ times more uncertain about foreign risks $\Lambda_{f}=(1+\alpha) \Lambda_{f}^{\star}$. We consider a $10 \%$ information advantage $(\alpha=0.1)$. Risk aversion is $\rho=2$. The supply of each asset has mean $\bar{x}$ $=100$ and standard deviation 10. Expected payoffs for home and foreign assets are equal. They are equally spaced between 1 and 2. The mean of the average investor's prior belief is the asset's true payoff. The standard deviation of prior beliefs is between 15-30\%, such that all assets have the same prior expected payoff to standard deviation ratio. To explore various levels of capacity, we transform $K$ into a more intuitive measure: $\tilde{K}=1-K^{-1 / 2}$ is how much an investor can reduce the standard deviation of one asset through learning. Following convention, home bias is

$$
\text { home bias }=1-\frac{1-\text { share of home asset in home portfolio }}{\text { share of foreign assets in world portfolio }} \text {. }
$$

In this example, as in the data, the share of foreign assets in the world portfolio is 0.5 . In a world where there is no initial information advantage and no learning capacity, home bias is zero. We use an economy with an initial information advantage, but no learning capacity as a benchmark. A $10 \%$ initial information advantage by itself generates a $5.3 \%$ home bias.

With uncorrelated assets, a home investor acquires information about one home asset and overweights that asset in his portfolio. When capacity can eliminate $22 \%$ of the standard deviation in one asset $(\tilde{K}=.22)$, home bias is $10 \%$, almost double its no-learning level. When $\tilde{K}=.70$, home bias is $45 \%$, more than eight times larger than the home bias without learning.

Asset Correlation Increases Home Bias Moderate correlation increases home bias because several home assets load on the one risk factor the investor learns about. When the investor has better information about more home assets, he tilts his portfolio more towards home risk. When home assets are positively correlated with each other, and foreign assets are positively correlated 
with each other (correlations of 10-30\%), but the two sets of assets are mutually uncorrelated, home bias doubles to $19.4 \%$ for $\tilde{K}=.22$. It increases to $59.5 \%$ for $\tilde{K}=.70$. (See line with circles in figure 2.) In contrast, the no learning benchmark is unaffected (5.3\%, line with diamonds). With $\tilde{K}=.82$, home bias is $72 \%$, just shy of the $76 \%$ in the data.

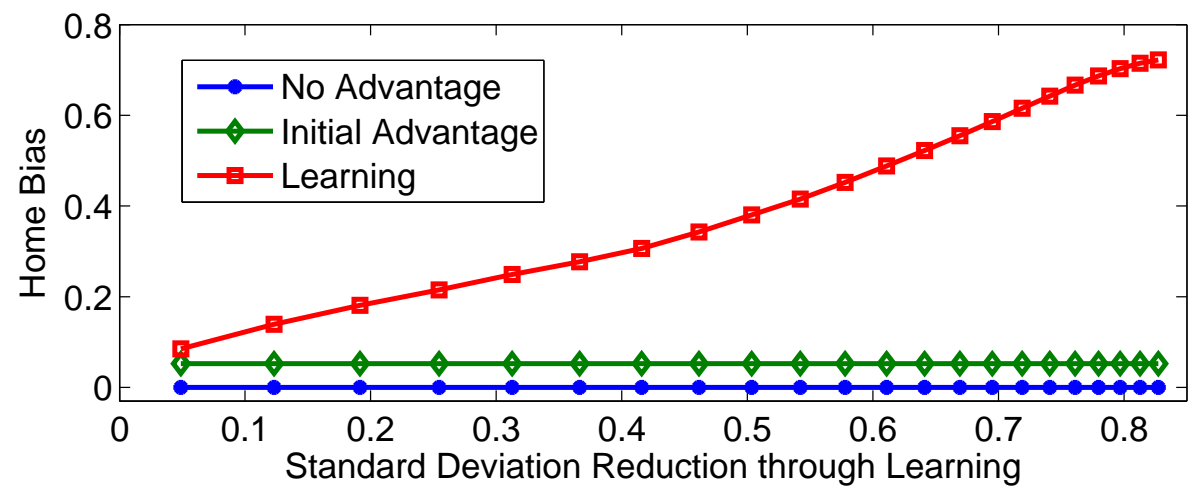

Figure 2: Home Bias Increases With Capacity. Assets within a country have correlated payoffs $\left(\operatorname{cov}=.09^{2}\right)$. Home bias is defined in (11). The 'no advantage' line (stars) is an economy with no initial informational advantage and no capacity to learn. The 'no learning' economy (diamonds) has a small initial information advantage (10\%) and no learning capacity. The 'learning' line (circles) is our model. Learning capacity $\mathrm{K}$ varies between 1.1 and 30 . The horizontal axis plots $\tilde{K}$, the potential percentage reduction in the standard deviation of one asset $\left(\tilde{K}=1-K^{-1 / 2}\right)$.

Local Information Increases Home Bias We use the same numerical example with correlated assets, except that instead of giving 1000 home (foreign) investors a 10\% initial information advantage in all 5 home (foreign) assets, we give 200 investors each a $50 \%$ advantage in one asset; the aggregate information advantages at home and abroad are unchanged. We measure local bias as in (11), treating localities like countries. With capacity $\tilde{K}=0.70$, local bias is $30 \%$. The average local investor holds 3.6 times what a diversified investor would hold, of his local asset.

Concentrating information advantages in local assets increases home bias. Without learning, the home bias is $8 \%$; with low capacity $(\tilde{K}=0.22)$, it is $23 \%$. With more capacity $(\tilde{K}=0.70)$, home bias is $76 \%$. This is $16.5 \%$ more than in in the previous case and matches the $76 \%$ home bias in the data. The underlying capacity level $K$ that matches the home bias in the local-advantage 
model is 3 times smaller than in the home country advantage model.

Inferring the level of capacity Portfolio out-performance provides clues about how much private information investors have. Ivkovic et al. (2007) use brokerage account data to show that individuals investors with concentrated portfolios earn $10 \%$ higher risk-adjusted annual returns on local, non-S\&P500 stocks than investors with diversified portfolios. Since the previous exercises show that correlated asset payoffs and local information advantages are important amplifiers of home bias, we continue with both assumptions.

To link the model to data, we equate the largest risk-factor in the home country ( $80 \%$ of market capitalization) with S\&P500 stocks (73\% of US market capitalization). For the non-S\&P risk factors, we compare expected returns of local investors, who learn about the local asset, and non-local investors. For the level of capacity that matches the empirical home bias $(\tilde{K}=.70)$, local investors' return on the smaller risk factors is $5 \%$ higher than what non-locals earn. The model can match Ivkovic et al. (2007)'s $10 \%$ result for $\tilde{K}=.75$. This inference suggests that the level of capacity required to match the home bias is not implausibly large.

Ivkovic et al. (2007) focus on non-S\&P500 stocks because their informational asymmetries are potentially the largest. They also report insignificant out-performance on the S\&P500 assets. While our model cannot speak to the statistical significance of their results, it does qualitatively match the pattern of lower out-performance on larger assets. For the calibration that matches the home bias, local investors' return on the largest risk factor (S\&P500 assets) is only 2\% higher than what non-locals earn. Returns fall on large assets because their size makes them valuable to learn about. Low average uncertainty about the risks makes equilibrium returns and out-performance low. 


\section{Seemingly Contradictory Evidence}

We discuss two facts that are inconsistent with the version of our model outlined so far. We show that both facts can be explained if we allow for asymmetric capacity. Asymmetric capacity is defined as heterogeneity in the parameter $K$ across investors. For this section, we think of two countries, a developed and an emerging market. We assume that capacity is homogenous across investors within the country. This heterogeneity in capacity across countries captures the more developed financial analysis sectors in developed economies.

Foreign Out-performance in Emerging Markets Using foreign investment data from Taiwan, Seasholes (2004) finds that foreign investors outperform the Taiwanese market, particularly in assets that are large and highly correlated with the macro-economy. He argues that "The results point to foreigners having better information processing abilities, especially regarding macrofundamentals." This conclusion leads us to ask two questions of our model.

Question 1: If Taiwanese investors have lower capacity than Americans, might Americans invest in Taiwanese assets and outperform the market? Recall that expected returns are determined by $\hat{\Lambda}^{a}$. If Americans have more capacity, they will reduce the average posterior variance for American assets by more: $\hat{\Lambda}_{h i}^{a}<\hat{\Lambda}_{f i}^{a \star}$, for equally-sized home and foreign risks $h i$ and $f i$. Therefore, expected returns for US assets will be lower than for Taiwanese assets. A large enough difference in returns will induce some Americans to invest in Taiwan and learn about Taiwan. If Americans have capacity that exceeds Taiwanese capacity, and the capacity gap exceeds their initial disadvantage in a Taiwanese risk factor, then Americans can become the best informed of any investor about that risk factor. Being best informed, the American will out-perform the average investor in assets that load on that factor. 
Question 2: Will American excess returns be concentrated in those Taiwanese assets that load heavily on the largest risk factors? Since section A shows that foreign investors learn about large assets with high market covariance, these are the Taiwanese assets American should out-perform on. Thus, an asymmetric capacity version of the model can reconcile high-capacity investors' outperformance at home, with their out-performance in emerging markets, for large high-beta assets.

The declining home bias The previous results imply that a rise in learning capacity $K$ should increase home bias. At first glance, these results seem to suggest that home bias should increase over time. If anything, the data point to a modest decline in the U.S. home bias. However, only a symmetric increase in capacity unambiguously increases home bias. If home investors' capacity increases more and home investors learn about home assets, then $\hat{\Lambda}_{i}^{a}$ will fall for home risk factors

$i$. This depresses home asset returns and home learning indices $\left(\frac{\partial \mathcal{L}_{i}}{\partial \hat{\Lambda}_{i}^{a}}>0\right)$, which may induce some home investors to learn about and hold more foreign equity. While this model can only make static predictions, these predictions suggest that a dynamic model with an asymmetric increase in capacity could reduce the average investor's home bias.

Furthermore, capital flow liberalization and increases in equity listings in the last 30 years have increased investible foreign risk factors (Bekaert, Harvey and Lundblad (2003)). The investors in our model would add these risk factors to the diversified part of their portfolio $(\bar{x})$. This effect would also increase foreign equity investment and reduce home bias.

\section{A New Direction for Estimating Information}

The fact that investors' information is inherently unobservable is an obstacle to assessing asymmetric information theories. One solution is to use proxies for investors' information, like the precision of earnings forecasts. But for many classes of investors, such proxies are not available. Our theory 
offers another solution. It delivers information sets as equilibrium outcomes. Observable features of assets predict information patterns, which in turn, predict observable portfolios, analyst behavior and pricing errors. This makes for testable hypotheses. A contribution of this paper is that it brings information-based theories to the data.

The novel part of this theory is the link it establishes between observable asset characteristics and the average investor's information, through the learning index. The following algorithm could be used to estimate learning indices: (i) Compute the eigen-decomposition (principal components) of asset payoffs. Payoffs are the dividend paid between $t$ and $t+1$ plus the price at $t+1: f_{t}=$ $d_{t}+p_{t+1}$. Post-multiply asset prices and payoffs by the eigenvector matrix $\Gamma$, to form risk factor prices and payoffs. Risk factor returns are $\Gamma^{\prime}\left(f_{t}-r p_{t}\right)$. (ii) Construct unconditional (prior) risk factor Sharpe ratios: Divide each risk factor's average return by its standard deviation. (iii) Estimate the coefficient $\Lambda_{B}$ from a regression of risk factor prices $\left(\Gamma^{\prime} p\right)$ on a constant and risk factor payoffs $\left(\Gamma^{\prime} f\right)$ - the risk factor counterpart to the price equation (15). Attributing the residual to asset supply shocks, the residual variance is $\Lambda_{C}^{2} \sigma_{x}^{2}$. One minus that regression's $R^{2}$ is $\Lambda_{p i} / \Lambda_{i}$ for an investor whose prior belief is based on past realizations of returns. ${ }^{12}$ (iv) Use the definition preceding proposition 2 to form each risk factor's learning index. (v) Pre-multiply the vector of risk factor indices by the eigenvector matrix $\Gamma$. The resulting vector contains learning indices for each asset. This procedure could also be applied to price and return indices across countries.

Learning indices could be used to test many aspects of the theory. (1) They should predict information-related variables such as analyst coverage. (2) Countries, regions or firms with higher learning indices should have lower returns, relative to what a standard model like the CAPM

\footnotetext{
${ }^{12}$ To derive the link between the regression $R^{2}$ and the learning index, manipulate (17) to get $C=-\rho \Sigma_{\eta}^{a}$. Square this equation and use (13) to get $C^{2} \sigma_{x}^{2}=\Sigma_{p}$. Since $C^{2} \sigma_{x}^{2}$ is the unexplained sum of squares in the price regression and $\Sigma$ is the total variance in prices, the regression $\left(1-R^{2}\right)$ is $\Sigma^{-1} \Sigma_{p}$, for assets and $\Lambda_{p i} / \Lambda_{i}$ for risk factor $i$.
} 
predicts. This is because assets with higher learning indices are ones that the average investor learns more about and thus is less uncertain about. Lower uncertainty $\hat{\Lambda}_{i}^{a}$ implies a lower return. (3) Finally, a country or region's learning index should be related to the home bias of its residents' portfolios. This relationship is non-monotonic. If the learning index is near zero, no one, not even locals learn about home risk. When all investors learn about foreign risk, there is only a small home bias that comes from initial information differences. As the home learning index grows, more home investors specialize in home risks. Information asymmetry and home bias rise. In the limit, as the home learning index grows very large, both home and foreign investors study home risks. Again, the small home bias comes only from the small differences in initial information. Because home bias depends on comparative information advantage, it is strongest for an intermediate level of the learning index.

\section{Conclusions}

This paper studies a common criticism of information-based models of the home bias: If home investors have less information about foreign stocks, why don't they choose to acquire foreign information, reduce their uncertainty about foreign payoffs, and undo their portfolio bias? The answer to this question requires a model where investors choose which risky asset payoffs to learn about. We show that investors who do not account for the effect of learning on portfolio choice, choose to undo their initial advantages. But, investors with rational expectations reinforce informational asymmetries. Investors learn more about risks they have an advantage in because they want their information to be very different from what others know. Thus our main message is that information asymmetry assumptions are defensible, but not for the reason originally thought. We do not need cross-border information frictions. With sufficient capacity to learn, small initial information 
advantages can lead to a home bias of the magnitude observed in the data.

A problem that many asymmetric information theories face is that unobservable information makes them difficult to evaluate empirically. While information cannot be observed, it can be predicted. A separate contribution of our paper is to connect the observed features of assets to predictions about investors' information sets. This connection provides a new way to bring information-based theories to the data.

An important assumption in our model is that every investor must process his own information. But paying one portfolio manager to learn for many investors is efficient. How might such a setting regenerate a home bias? Because monitoring information collection is difficult, portfolio managers have an incentive to lie about how much research they do. Investors may want to occasionally audit portfolio managers. Having a manager from the same region, with similar initial information, is advantageous because checking the manager's work requires less capacity. Portfolio managers with the same initial information advantage as their clients form the same optimal portfolio as would a client who processed information himself. This optimal portfolio is home biased. Future work could use the framework in this model to build an equilibrium model of delegated portfolio management.

The broader message of our paper is that investors choose to have different information sets. The standard asset pricing and portfolio choice models typically assume symmetric information sets across agents. Our paper shows that these models are subject to an important criticism: Investors have an incentive to deviate by learning information that others do not know. 


\section{Appendix}

\section{A Proof of Proposition 1}

The optimization problem is $\max _{\hat{\Lambda}} \sum_{i} \tilde{q}^{2} \hat{\Lambda}_{i}$ s.t. $\hat{\Lambda}_{i} \leq \Lambda_{i}$ and $\prod_{i} \hat{\Lambda}_{i} \geq \prod_{i} \Lambda_{i} \frac{1}{K}$, where $\tilde{q}=\Gamma_{i}^{\prime} q, \forall i$. The first-order condition for this problem is $\tilde{q}^{2}-v \frac{1}{\hat{\Lambda}_{i}} \prod_{l} \hat{\Lambda}_{l}+\phi_{i}=0$ where $v$ is the Lagrange multiplier on the capacity constraint and $\phi_{i}$ is the Lagrange multiplier on the no-negative-learning constraint for asset $i$. We conjecture and then verify that if $K>K^{\star}$, the no negative learning constraint does not bind $\left(\phi_{i}=0\right)$. This implies that $\hat{\Lambda}_{i}=\frac{v}{\tilde{q}^{2} K} \prod_{i} \Lambda_{i}$. Taking a product on both sides and imposing the capacity constraint yields $v=\tilde{q}^{2}\left(K \prod_{i} \Lambda_{i}\right)^{\frac{N-1}{N}}$. Substituting this in the first-order condition delivers $\hat{\Lambda}_{i}=\left(\frac{1}{K} \prod_{i} \Lambda_{i}\right)^{\frac{1}{N}} \equiv M$. Note that $M$ is monotonically decreasing in capacity $K$, which verifies our conjecture.

The cutoff capacity level $K^{\star}$ solves $\min _{i}\left\{\Lambda_{i}\right\}=\left(\frac{1}{K^{\star}} \prod_{i} \Lambda_{i}\right)^{\frac{1}{N}}$. The result that $\hat{\Lambda}_{i}=\min \left\{\Lambda_{i}, M\right\}$ for $K<K^{\star}$ follows from imposing the no-negative learning constraint, which states that if $\phi_{i}>0$ then $\hat{\Lambda}_{i}=\Lambda_{i}$.

\section{B Equilibrium Asset Prices}

Let $\Sigma_{\eta j}$ be the variance-covariance matrix of the private signals that investor $j$ chooses to observe. The following three precision matrices are useful in deriving the pricing function. $\left(\Sigma_{\eta}^{a}\right)^{-1}$ is the average precision of investors' information advantage, plus the average precision of the information they choose to learn. $\left(\Sigma_{p}\right)^{-1}$ is the precision of prices as a signal about true payoffs. $\left(\widehat{\Sigma}^{a}\right)^{-1}$ is the average of all investors' posterior belief precisions, taking into account priors, signals and prices.

$$
\begin{aligned}
& \left(\Sigma_{\eta}^{a}\right)^{-1}=\Gamma\left(\Lambda_{\eta}^{a}\right)^{-1} \Gamma^{\prime}=\frac{1}{2} \Sigma^{-1}+\frac{1}{2}\left(\Sigma^{\star}\right)^{-1}+\int_{j}\left(\Sigma_{\eta}^{j}\right)^{-1} d j \\
& \left(\Sigma_{p}\right)^{-1}=\Gamma \Lambda_{p}^{-1} \Gamma^{\prime}=\frac{1}{\rho^{2} \sigma_{x}^{2}}\left(\Sigma_{\eta}^{a} \Sigma_{\eta}^{a^{\prime}}\right)^{-1} \\
& \left(\widehat{\Sigma}^{a}\right)^{-1}=\quad \Gamma \hat{\Lambda}_{a}^{-1} \Gamma^{\prime}=\frac{1}{\rho^{2} \sigma_{x}^{2}}\left(\Sigma_{\eta}^{a} \Sigma_{\eta}^{a^{\prime}}\right)^{-1}+\left(\Sigma_{\eta}^{a}\right)^{-1}
\end{aligned}
$$

We assumed that investors cannot not change the risk factor structure, implying $\Sigma_{\eta}$ has eigenvectors $\Gamma$. Since sums, products and inverses preserve eigenvectors, $\Sigma_{\eta}^{a}, \Sigma_{p}$, and $\widehat{\Sigma}^{a}$ share the same eigenvectors as well. 
Setting asset demand $\int_{j} q_{j}$ equal to asset supply $\bar{x}+x$ delivers the equilibrium price:

$$
\begin{aligned}
r p & =A+f+C x \quad \text { where } \\
A & =-\rho\left(\frac{1}{\rho^{2} \sigma_{x}^{2}}\left(\Sigma_{\eta}^{a} \Sigma_{\eta}^{a^{\prime}}\right)^{-1}+\left(\Sigma_{\eta}^{a}\right)^{-1}\right)^{-1} \bar{x} \\
C & =-\left(\frac{1}{\rho^{2} \sigma_{x}^{2}}\left(\Sigma_{\eta}^{a} \Sigma_{\eta}^{a^{\prime}}\right)^{-1}+\left(\Sigma_{\eta}^{a}\right)^{-1}\right)^{-1}\left(\rho I+\frac{1}{\rho \sigma_{x}^{2}}\left(\Sigma_{\eta}^{a}\right)^{-1^{\prime}}\right) .
\end{aligned}
$$

This result is almost identical to Admati (1985), except that Admati's investors have common priors, while we treat priors as though they were private signals.

This result delivers two useful expressions used in the text. First, $C=-\rho \Sigma_{\eta}^{a}$ and therefore, $C C^{\prime} \sigma_{x}^{2}=$ $\rho^{2} \sigma_{x}^{2} \Sigma_{\eta}^{a} \Sigma_{\eta}^{a \prime}=\Sigma_{p}$. Second, expected risk factor returns are

$$
\Gamma_{i}^{\prime} E[f-p r]=-\Gamma_{i}^{\prime} A=\rho \Gamma_{i}^{\prime} \hat{\Sigma}^{a} \bar{x}=\rho \Gamma_{i}^{\prime} \Gamma \hat{\Lambda}^{a} \Gamma^{\prime} \bar{x}=\rho\left(\Gamma_{i}^{\prime} \bar{x}\right) \hat{\Lambda}_{i}^{a}
$$

where the first equality follows from (15), the second from (14) and (16), the third from $\hat{\Sigma}^{a}=\Gamma \hat{\Lambda}^{a} \Gamma^{\prime}$, and the last equality follows from $\Gamma^{\prime} \Gamma=I$.

\section{Proof of Proposition 2}

We begin by redefining the objective in (9) as $\max _{y_{i}^{j}} \quad \sum_{i}\left(\Lambda_{p i}+\left(\rho \Gamma_{i}^{\prime} \bar{x} \hat{\Lambda}_{i}^{a}\right)^{2}\right)\left(\left(\Lambda_{i}^{j}\right)^{-1}+\Lambda_{p i}^{-1}\right) y_{i}^{j}$, where $y_{i}^{j}$ is the ratio of posterior precision to the precision of priors plus price information, about risk $i$ for investor $j:\left(\hat{\Lambda}_{i}^{j}\right)^{-1} /\left(\left(\Lambda_{i}^{j}\right)^{-1}+\Lambda_{p i}^{-1}\right)$. The capacity constraint (3) is equivalent to $\left(\prod_{i} y_{i}\right)\left(\prod_{i}\left(\Lambda_{i}^{-1}+\Lambda_{p i}^{-1}\right) / \Lambda_{i}^{-1}\right) \leq K$. Then, define $\hat{K}$ to be the investors' 'spare capacity' that is left over to be allocated after he processes information in prices: $\hat{K}=K \prod_{i} \Lambda_{i}^{-1} /\left(\Lambda_{i}^{-1}+\Lambda_{p i}^{-1}\right)$. The capacity constraint becomes $\prod_{i} y_{i} \leq \hat{K}$. We endow the investor with enough spare capacity to acquire private signals after devoting capacity to learning from prices: $\hat{K}>1$. Finally, the no-negative-learning constraint (4) becomes $y_{i} \geq 1 \forall i$.

This problem maximizes a sum subject to a product constraint. The second order condition for this problem is positive, meaning the optimum is a corner solution. A simple variational argument shows that the 
maximum is attained by maximizing the $y_{i}$ with the highest learning index $\left(\Lambda_{p i}+\left(\rho \Gamma_{i}^{\prime} \bar{x} \hat{\Lambda}_{i}^{a}\right)^{2}\right)\left(\left(\Lambda_{i}^{j}\right)^{-1}+\Lambda_{p i}^{-1}\right)$. For all risk factors $k$ that he does not learn about, the investor sets $y_{k}=1$.

\section{Proof of Proposition 3}

Substituting the formula for posterior variances into the inequality in the proposition, $\Lambda_{h}^{-1}+\Lambda_{p h}^{-1}+\Lambda_{\eta h}^{-1}-$ $\left(\hat{\Lambda}_{h}^{*}\right)^{-1}-\Lambda_{p h}^{-1}-\left(\Lambda_{\eta h}^{*}\right)^{-1} \geq \Lambda_{p h}^{-1}-\left(\Lambda_{\eta h}^{*}\right)^{-1}$, where $\Lambda_{\eta h}^{-1}\left(\left(\Lambda_{\eta h}^{*}\right)^{-1}\right)$ are the signal precision obtained by the average home (foreign) investors about risk factor $h$. Cancelling terms yields $\Lambda_{\eta h}^{-1} \geq\left(\Lambda_{\eta h}^{*}\right)^{-1}$.

Every home investor who learns about risk $i$ gets signal precision $\Lambda_{\eta i}^{-1}=(\hat{K}-1)\left(\Lambda_{i}^{-1}+\Lambda_{p i}^{-1}\right)$ and every foreign investor who learns about $i$ gets signal precision $\Lambda_{\eta i}^{-1}=(\hat{K}-1)\left(\left(\Lambda_{i}^{*}\right)^{-1}+\Lambda_{p i}^{-1}\right)$. Since the initial information advantage means that $\Lambda_{i}^{-1}>\left(\Lambda_{i}^{*}\right)^{-1}$ for any home risk factor $i$, it also implies that $\Lambda_{\eta i}^{-1}>\Lambda_{\eta i}^{-1}$, if both investors learn about home risk factor $i$. Let $\xi_{h}\left(\xi_{h}^{\star}\right)$ be the probability that a home (foreign) investor learns about some home risk $h$. Then the signal precision of the average home and foreign investor is $\xi_{i} \Lambda_{\eta i}^{-1}$ and $\xi_{i}^{*}\left(\Lambda_{\eta i}^{*}\right)^{-1}$. A sufficient condition for the average home signal precision to be larger than the average foreign signal precision is if $\xi_{h} \geq \xi_{h}^{\star}$. The last step establishes this inequality.

The learning index for home risk factor $h$ is always greater for a home investor: $\Lambda_{p h} \Lambda_{h}^{-1}+\left(\hat{\Lambda}_{h}^{a} \Gamma_{h}^{\prime} \bar{x}\right)^{2}\left(\Lambda_{h}^{-1}+\right.$ $\left.\Lambda_{p h}^{-1}\right)>\frac{\Lambda_{p h}}{\Lambda_{h}^{\star}}+\frac{\left(\hat{\Lambda}_{h}^{a}\right)^{2}}{\Lambda_{h}^{\star}}\left(\Gamma_{h}^{\prime} \bar{x}\right)^{2}$ because $\Lambda_{h}=\Lambda_{h}^{\star} \alpha$, for $\alpha<1$. Since we are looking at the symmetric mixed strategy equilibrium (see footnote 8), this implies that $\xi_{h} \geq \xi_{h}^{\star}$, for every home risk factor $h$.

\section{E Proof of Proposition 4}

Using equation (10) and the definition of $q^{\text {no learn }}$, we can write the difference in home bias for these two portfolios. The optimal portfolio of investor $j$ contains at least as much of some home risk factor $i$ iff

$$
\left(\hat{\Lambda}_{i}^{j}\right)^{-1} \hat{\Lambda}^{a} \geq \frac{\left(\Lambda_{i}^{j}\right)^{-1}+\Lambda_{p i}^{-1}}{\Lambda_{i}^{-1} / 2+\left(\Lambda_{i}^{*}\right)^{-1} / 2+\Lambda_{p i}^{-1}} .
$$

Let $\xi_{i}\left(\xi_{i}^{\star}\right)$ be the probability that a home (foreign) investor learns about some home risk $i$. Using Bayes' law (6) and averaging across investors, we can rewrite $\left(\hat{\Lambda}_{i}^{a}\right)^{-1}=1 / 2\left(\Lambda_{i}^{-1}+\left(\Lambda_{i}^{*}\right)^{-1}\right)+\Lambda_{p i}^{-1}+\xi_{i}(\hat{K}-$ 
1) $\left(\Lambda_{i}^{-1}+\Lambda_{p i}^{-1}\right) / 2+\xi_{i}^{*}(\hat{K}-1)\left(\left(\Lambda_{i}^{*}\right)^{-1}+\Lambda_{p i}^{-1}\right) / 2$. Likewise, the average home posterior precision is $\left(\hat{\Lambda}_{i}^{j}\right)^{-1}=$

$\left(1+\xi_{i} \hat{K}\right)\left(\Lambda_{i}^{-1}+\Lambda_{p i}^{-1}\right)$. Substituting these two equations into (19) and canceling terms yields $1+\xi_{i} \hat{K} \geq 1+\xi_{i}^{\star} \hat{K}$.

From the proof of proposition 3, we know that $\xi \geq \xi_{i}^{\star}$, for every home risk factor $i$. Since the learning portfolio of a home investor contains at least much of every home risk factor as the no learning portfolio does, $E\left[\bar{\Gamma}_{h}^{\prime} q\right]>E\left[\bar{\Gamma}_{h}^{\prime} q^{\text {no learn }}\right]$. By the same logic, $E\left[\bar{\Gamma}_{f}^{\prime} q\right]>E\left[\bar{\Gamma}_{f}^{\prime} q^{\text {no learn }}\right]$ for a foreign investor.

\section{References}

Admati, Anat, 1985, A noisy rational expectations equilibrium for multi-asset securities markets, Econometrica 53(3), 629-57.

Admati, Anat, and Paul Pfleiderer, 1990, Direct and indirect sale of information, Econometrica $58(4), 901-28$.

Ahearne, Alan, William Griever, and Francis Warnock, 2004, Information costs and home bias: An analysis of us holding of foreign equities, Journal of International Economics 62, 313-36.

Bacchetta, Philippe, and Eric van Wincoop, 2006, Can information heterogeneity explain the exchange rate determination puzzle?, American Economic Review 96(3), 552-576.

Bae, Kee-Hong, Rene Stulz, and Hongping Tan, 2008, Do local analysts know more? a crosscountry study of the performance of local analysts and foreign analysts, Journal of Financial Economics forthcoming.

Banerjee, Snehal, 2007, Learning from prices and the dispersion in beliefs, Working paper, Northwestern University.

Bekaert, Geert, Campbell Harvey, and Christian Lundblad, 2003, Equity market liberalization in emerging markets, Journal of Financial Research 26, 275-299. 
Botosan, Caval, 1997, Disclosure level and the cost of equity capital, The Accounting Review 72, $323-349$.

Boyle, Phelim, Raman Uppal, and Tan Wang, 2003, Ambiguity aversion and the puzzle of owncompany stock in pension plans, Working paper, London Business School.

Brennan, Michael, and Henry Cao, 1997, International portfolio investment flows, The Journal of Finance 52, 1851-80.

Calvo, Guillermo, and Enrique Mendoza, 2000, Rational contagion and the globalization of securities markets, Journal of International Economics 51(1), 79-113.

Choe, Hyuk, Bong-Chan Kho, and Rene M. Stulz, 2005, Do domestic investors have an edge? the trading experience of foreign investors in Korea, Review of Financial Studies 18(3), 795-829.

Cohen, Lauren, 2007, Loyalty based portfolio choice, Review of Financial Studies forthcoming.

Cohen, Lauren, Andrea Frazzini, and Christopher Malloy, 2007, The small world of investing: Board connections and mutual fund returns, NBER Working paper \#13121.

Cole, Harold, George Mailath, and Andrew Postlewaite, 2001, Investment and concern with relative position, Review of Economic Design 6(2), 241-261.

Coval, Joshua, 2003, International capital flows when investors have local information, Working paper, Harvard Business School.

Coval, Joshua, and Tobias Moskowitz, 2001, The geography of investment: Informed trading and asset prices, Journal of Political Economy 109(4), 811-41. 
Cover, Thomas, and Joy Thomas, 1991, Elements of Information Theory (John Wiley and Sons, New York, New York), first edition.

DeMarzo, Peter, Ron Kaniel, and Ilan Kremer, 2004, Diversification as a public good: Community effects in portfolio choice, The Journal of Finance 59(4), 1677-1715.

Dow, James, Itay Goldstein, and Alexander Guembel, 2007, Incentives for information production in markets where prices affect real investment, Working paper, Wharton.

Dvorak, Tomas, 2007, Do domestic investors have an information advantage? evidence from Indonesia, The Journal of Finance 60(2), 817-839.

Easley, David, Soeren Hvidkjaer, and Maureen O'Hara, 2002, Is information risk a determinant of asset returns?, The Journal of Finance 57(5), 2185-2221.

Evans, Martin, and Richard Lyons, 2005, A new micro model of exchange rate dynamics, Working paper, Georgetown University.

French, Kenneth, and James Poterba, 1991, International diversification and international equity markets, American Economic Review 81(2), 222-26.

Glodjo, Arman, and Campbell Harvey, 1994, Forecasting foreign exchange market movements via entropy coding, Working paper, Duke University.

Graham, John, Campbell Harvey, and Hai Huang, 2006, Investor competence, trading frequency, and home bias, Working paper, Duke University.

Greenstone, Michael, Paul Oyer, and Annette Vissing-Jorgensen, 2006, Mandated disclosure, stock returns, and the 1964 securities acts amendments, The Quarterly Journal of Economics 121, $2399-460$. 
Grossman, Sanford, and Joseph Stiglitz, 1980, On the impossibility of informationally efficient markets, American Economic Review 70(3), 393-408.

Guiso, Luigi, and Tullio Jappelli, 2006, Information acquisition and portfolio performance, CEPR working paper \#5901.

Hansen, Lars, and Thomas Sargent, 2001, Robust control and model uncertainty, American Economic Review 91(2), 60-66.

Hau, Harald, 2001, Location matters: An examination of trading profits, Journal of Finance 56(5), 1959-83.

Huberman, Gur, 2001, Familiarity breeds investment, Review of Financial Studies 14(3), 659-80.

Ivkovic, Zoran, Clemens Sialm, and Scott Weisbenner, 2007, Portfolio concentration and the performance of individual investors, Journal of Financial and Quantitative Analysis forthcoming.

Ivkovic, Zoran, and Scott Weisbenner, 2005, Local does as local is: Information content and the geography of individual investors' common stock investments, Journal of Finance 60, 267-306.

Kacperczyk, Marcin, Clemens Sialm, and Lu Zheng, 2005, On the industry concentration of actively managed equity mutual funds, Journal of Finance 60(4), 1983-2011.

Kang, Jun-Koo, and Rene Stulz, 1997, Why is there a home bias? an analysis of foreign equity ownership in Japan, Journal of Financial Economics 46(1), 3-28.

Lewis, Karen, 1999, Trying to explain home bias in equities and consumption, Journal of Economic Literature 37, 571-608.

Malloy, Christopher, 2005, The geography of equity analysis, Journal of Finance 60, 719-755. 
Massa, Massimo, and Andrei Simonov, 2006, Hedging, familiarity and portfolio choice, The Review of Financial Studies 19(2), 633-685.

Morse, Adair, and Sophie Shive, 2008, Patriotism in your portfolio, Working paper, University of Chicago.

Moscarini, Giuseppe, 2004, Limited information capacity as a source of inertia, Journal of Economic Dynamics and Control 28(10), 2003-35.

Ozdenoren, Emre, and Kathy Yuan, 2007, Feedback effects and asset prices, Journal of Finance forthcoming.

Pastor, Lubos, 2000, Portfolio selection and asset pricing models, Journal of Finance 55(1), 179223.

Pastor, Lubos, and Pietro Veronesi, 2003, Stock valuation and learning about profitability, Journal of Finance 58(5), 1749-89.

Peress, Joel, 2006, The tradeoff between risk sharing and information production in financial markets, Working paper, INSEAD.

Portes, Richard, Helene Rey, and Yonghyup Oh, 2001, Information and capital flows: The determinants of transactions in financial assets, European Economic Review 45, 783-96.

Seasholes, Mark, 2004, Re-examining information asymmetries in emerging stock markets, Working paper, Haas School of Business.

Shannon, Claude E., 1948, Mathematical theory of communication, Bell System Technology Journal 27, 379-423 and 623-656. 
Shukla, Ravi, and Greg van Inwegen, 1995, Do locals perform better than foreigners?: An analysis of UK and US mutual fund managers, Journal of Economics and Business 47(3), 241254.

Sims, Christopher, 2003, Implications of rational inattention, Journal of Monetary Economics $50(3), 665-90$.

Tesar, Linda, and Ingrid Werner, 1998, The internationalization of securities markets since the 1987 crash, Brookings-Wharton Papers on Financial Services, The Brookings Institution.

Uppal, Raman, and Tan Wang, 2003, Model misspecification and underdiversification, Journal of Finance 58(6), 2465-2486.

Van Nieuwerburgh, Stijn, and Laura Veldkamp, 2008, Information acquisition and underdiversification, Working paper, New York University.

Yuan, Kathy, 2005, Asymmetric price movements and borrowing constraints: A rational expectations equilibrium model of crisis, contagion, and confusion, Journal of Finance 60(1), 379-411. 